\title{
An Epidemiological Study of Diagnosed Avascular Necrosis of Hip Joint (AVN Hip) Cases and Exploring the Etiology and Treatment Offered in Patients Coming to Dr. Hardas Singh Orthopedic Hospital and Superspeciality Research Centre, Circular Road, Amritsar, Punjab
}

Dr. Pancham Prasad*, Dr. Parvinder Singh Sandhu

HOD, Department of Orthopedic, Dr. Hardas Singh Orthopedic Hospital and Superspeciality Research Centre, Circular Road, Amritsar, Punjab, India

DOI: $10.36347 / \mathrm{sajb} .2020 . \mathrm{v} 08 \mathrm{i} 11.001$

| Received: 01.11.2020 | Accepted: 07.11.2020| Published: 13.11.2020

*Corresponding author: Dr. Pancham Prasad

Abstract

Original Research Article

Background: Osteonecrosis is a condition caused by a temporary or permanent loss of blood flow to the bone. Data regarding the incidence and prevalence of AVN hip in Indian scenario is not clear, studies which are of recent origin estimate the prevalence or presence of disease based on North Indian population as having more males involved than females without any clear picture regarding the prevalence in general population. Study was planned to get a clear picture in the hospital settings as to what can be the possible causes of AVN hip and treatment being given to such cases. Material and methods: Hospital based study on patients coming to the Orthopedics OPD of Dr. Hardas Singh Orthopedic hospital and superspeciality research centre was conducted from June 2018-June 2020. Data was collected for willing patients and analyzed using SPSS version 20.0. Results: 139 Males were affected mostly out of 158 patients, the common reasons behind the cause of AVN hip were Chronic diseases, Idiopathic reasons and Smoking. Treatment in form of Surgery was refused by 43 individuals while 115 patients were upon and core decompression, vascularized fibular bone graft and total hip replacement was the commonest option given. Conclusion: More research is needed on this topic and patient education is needed to make them seek early medical care.

Keywords: Osteonecrosis, AVN hip, Orthopedics, patients, Surgery.

Copyright $\odot 2020$ The Author(s): This is an open-access article distributed under the terms of the Creative Commons Attribution 4.0 International License (CC BY-NC 4.0) which permits unrestricted use, distribution, and reproduction in any medium for non-commercial use provided the original author and source are credited.

\section{AbBreviation}

AVN-avascular necrosis of hip

THR-total hip replacement

HHS- harris hip score

ARCO- Association Research Circulation Osseous

ONFH-osteonecrosis of femur head

\section{INTRODUCTION}

Osteonecrosis is a condition caused by a temporary or permanent loss of blood flow to the bone. Blood transports the bones with vital nutrients and oxygen [1]

The bone tissues (osteo) start breaking down (necrosis) when the blood flow is disrupted. This can weaken the bone and result in its breakdown eventually. If this happens near a joint, it may cause the surface of the joint to collapse, leading to pain and inflammation (arthritis) [2].
Avascular necrosis or 'AVN', 'aseptic necrosis' and 'ischemic bone necrosis' are often referred to as osteonecrosis [3].

AVN most of the time It occurs in the hip joint (femoral head) but can also occur in other anatomical locations (e.g. elbow, knee, and ankle). The incidence of $\mathrm{ON}$ in the sample population in the United Kingdom between 1989 and 2003 was between 1.4 and 3.0 per 100 000. The hip joint was mainly involved, accounting for $75.9 \%$ of cases [4].

Epidemiological data have been identified in the United States pegging the prevalence of Avascular Necrosis hip in the general population around 300000 to 600000 cases in early 2000s. The onset of the disease remains stable and stable. About 10000 to 20000 new cases each year [5].

These values are comparable to those in other countries as well .Analysis of the Japanese population shows an occurrence Rate of 1.9 per 100000 [6]. 
The average age of the affected population patients are 47 years of age and the ratio of male to female is $3: 1$. In the Canadian, Swedish and Australian registries it has been shown that Avascular Necrosis of Hip accounts for around $2.8 \%$ percent of the primary overall hip replacements [7].

Early diagnosis is also important, since it ultimately affects young people and the middle-aged generation, and because of the progression it is seen in the collapse of the femoral head. Up to 80 per cent of patients are left untreated [8].

In addition, if this is not the case the disease will affect both hips in between $40 \%$ and $70 \%$ of cases as based on published evidence [9].

Till date, data regarding the incidence and prevalence of AVN hip in Indian scenario is not clear, studies which are of recent origin estimate the prevalence or presence of disease based on North Indian population as having more males involved than females without any clear picture regarding the prevalence in general population [10].

Traditionally with the available the etiology has been declared to be multifactorial including a genetic predilection and due to some risk factors. They have been unanimously named as chronic corticosteroid administration, chronic alcohol drinking, smoking, chronic diseases like kidney disease, various forms of leading hemoglobinopathies to anemias, inflammatory diseases, hypertension, gout and transplantation rejection [11].

Treatment of AVN Hip depends on the extent of injury involved and are usually non operative like restricted weight bearing, using pharmacological agents like lipid-lowering drugs, anticoagulants, vasodilators, and bisphosphonates. While the operative options involve various processes like core decompression best used for Grade 1 and Grade 2 AVN hip and newer modalities which include vascularized free-fibula grafting, total hip resurfacing and the total hip arthroplasty which is most effective in reducing pain and preferable for young patients $[12,13]$.

Data regarding the prevalence or various etiologies for the cause of Avascular necrosis of hip joint (AVN Hip) in various states remains a distant goal given the current paucity of data and research in India. We expect a preliminary data analysis based on patient register will give us an idea about the possible extent of disease prevalence in the state of Punjab along with giving a further direction to understand the disease better in the population of Punjab which is tribal predominant and usually is afflicted with hemoglobinopathies like Sickle cell anemia and Thalassemia. The objectives ascertained were 1) To detail the epidemiological profile of the patients coming with AVN Hip 2) To detail out the various etiologies of AVN Hip in the patients studied 3) To enumerate the various treatment given to the patients [14].

\section{METHODS}

After obtaining the permission from Institutional Ethical Committee this study on patients records over a period of last one year was initiated. Willing patients who participated in the study were followed up to week without relevant details as to their habits or presence of diseases etc. Study period was for two years June 2018-June 2020.

A total of 158 participants were asked various relevant probing questions based on the structured questionnaire designed in the department of Orthopedics in Dr. Hardas Singh orthopedic Hospital.

Harris Hip Score (HHS) was done to evaluate the functionality of the hip joint along with various clinical, radiological and physical examination to ascertain the diagnosis and other necessary relevant things. CT scans and MRIs were performed as per standard protocol accepted over the globe, the revised criteria proposed by Research Committee on Idiopathic Osteo Necrosis Femoral Head in Japan, while ARCO (Association Research Circulation Osseous) was used to stage the extent of disease $[15,16]$.

All patients diagnosed as AVN Hip with traumatic and non-traumatic etiologies were included in the study. Participants were asked about smoking, diet, personal family history, usage of drug for more than six months regularly and associated systemic disease. Detailed information on the level and length of alcohol intake has been reported in patients with a history of alcoholism. For steroids, correct information was collected on the indication, regimen, dose, and adverse effect or complications.

Information of injury, length of the injury to the operation / intervention, surgery and assessment methods of ONFH were collected in posttraumatic conditions. Routine laboratory tests such as complete blood count, renal function test, liver function test, lipid profile and coagulation profile (such as prothrombin time, clotting time, and partial thromboplastin activation time) were performed for all patients. Patients without any confirmed association of disease leading to AVN Hip were labelled as idiopathic.

There were 158 participants and 296 hip joints affected (138 bilateral and 20 unilateral) 115 patients were treated with surgical methods while 43 patients refused to be treated surgically. Rest were managed with pharmacological agents. 


\section{DATA ANALYSIS}

All data were recorded on MS excel sheets which were later analyzed using SPSS version 20.0. Qualitative data were expressed using the measures of central tendency while measures of association like Chi square tests or Man Whitney test for skewed data were used. Normalcy of data distribution for various variables were checked using Kolmogorov-Smirnov Test of Normality. Categorical values were described as frequencies and proportions. Statistical significance was determined after two tail tests and if the $\mathrm{p}$ value was $<.05$ it was considered to be of statistical significance.

\section{RESULTS}

Out of 158 patients we had 138 patients with both sides of hip involved while 20 had unilateral hip involved. A total of 296 hips were afflicted. 229 Hips were surgically treated while 67 hips were given the treatment with pharmacological agents.

We met with 40 refusals for surgical treatment. We had more male in our study $88 \%$ while only 19 females. The age group involved had a wide range of 18-79 years with mean age 51.945 years.

A chi square test of association after checking the normalcy of data shows the gender and age distribution to be of statistical significance, while that with religion was found to be also significant .Association of gender with residents and socioeconomic status were not statistically significant.

Majority of the participants were from urban area and above poverty line (Table-1) 138 patients had a bilateral hip AVN, we evaluated the Harris Hip Score and various etiologies which could have caused the AVN hip. Chronic diseases like renal failure, hypertension and diabetes, smoking and idiopathic onset of AVN hip were the major reasons in our study findings and were statistically significant when chi square tests were applied to measure the association (Table-2). In our study we also found that the Sides involved, Harris Hip score and ACRO staging were associated with statistical significance with the treatment modalities (Table-3). On applying the chi square test among the various surgical options chosen and ACRO staging we found that this was of high statistical significance (Table-4). In our study majority were offered Core decompression and vascularized free fibular graft.

The mean HHS in unilateral ONFH was $74.97 \pm$ 14.35. With majority of cases falling in the category of $70-79$ followed by category of $<70$, both constituting around $74 \%$.

Table-1: Table describing in detail the association with age, socio economic status, religion, and residence with gender

\begin{tabular}{|c|c|c|c|c|c|}
\hline & \multicolumn{2}{|c|}{ Gender } & \multirow[t]{2}{*}{ Total } & \multirow[t]{2}{*}{ p value } \\
\hline & & Male & Female & & \\
\hline \multirow[t]{10}{*}{ Age in Years } & \multirow[t]{2}{*}{$18-25$} & 12 & 1 & 13 & \multirow[t]{10}{*}{0.046} \\
\hline & & $7.6 \%$ & $.6 \%$ & $8.2 \%$ & \\
\hline & \multirow[t]{2}{*}{$26-40$} & 17 & 2 & 19 & \\
\hline & & $10.8 \%$ & $1.3 \%$ & $12.0 \%$ & \\
\hline & \multirow[t]{2}{*}{$41-54$} & 46 & 8 & 54 & \\
\hline & & $29.1 \%$ & $5.1 \%$ & $34.2 \%$ & \\
\hline & \multirow[t]{2}{*}{$55-65$} & 44 & 1 & 45 & \\
\hline & & $27.8 \%$ & $.6 \%$ & $28.5 \%$ & \\
\hline & \multirow[t]{2}{*}{ 66-79 } & 20 & 7 & 27 & \\
\hline & & $12.7 \%$ & $4.4 \%$ & $17.1 \%$ & \\
\hline \multirow[t]{8}{*}{ Religion } & \multirow[t]{2}{*}{ Hindu } & 56 & 1 & 57 & \multirow[t]{8}{*}{0.003} \\
\hline & & $33.0 \%$ & $.9 \%$ & $33.9 \%$ & \\
\hline & \multirow[t]{2}{*}{ Muslim } & 44 & 12 & 65 & \\
\hline & & $28.4 \%$ & $8.3 \%$ & $36.7 \%$ & \\
\hline & \multirow[t]{2}{*}{ Christian } & 21 & 0 & 21 & \\
\hline & & $18.3 \%$ & $0.0 \%$ & $18.3 \%$ & \\
\hline & \multirow[t]{2}{*}{ Others } & 18 & 6 & 24 & \\
\hline & & $11.0 \%$ & $0.0 \%$ & $11.0 \%$ & \\
\hline \multirow[t]{4}{*}{ Residence } & \multirow[t]{2}{*}{ Urban } & 54 & 8 & 62 & \multirow[t]{4}{*}{0.785} \\
\hline & & $34.2 \%$ & $5.1 \%$ & $39.2 \%$ & \\
\hline & \multirow[t]{2}{*}{ Rural } & 85 & 11 & 96 & \\
\hline & & $53.8 \%$ & $7.0 \%$ & $60.8 \%$ & \\
\hline \multirow[t]{4}{*}{ SES } & \multirow[t]{2}{*}{ APL } & 90 & 14 & 104 & \multirow[t]{4}{*}{0.441} \\
\hline & & $57.0 \%$ & $8.9 \%$ & $65.8 \%$ & \\
\hline & \multirow[t]{2}{*}{ BPL } & 49 & 5 & 54 & \\
\hline & & $31.0 \%$ & $3.2 \%$ & $34.2 \%$ & \\
\hline \multirow{2}{*}{\multicolumn{2}{|c|}{ Total }} & 139 & 19 & 158 & \\
\hline & & $88.0 \%$ & $12.0 \%$ & $100.0 \%$ & \\
\hline
\end{tabular}


Pancham Prasad \& Parvinder Singh Sandhu., Sch Acad J Biosci, Nov, 2020; 8(11): 344-349

Table-2: An association between Harris Hip Score, ACRO Staging, and Side Involved with Various Aetiologies

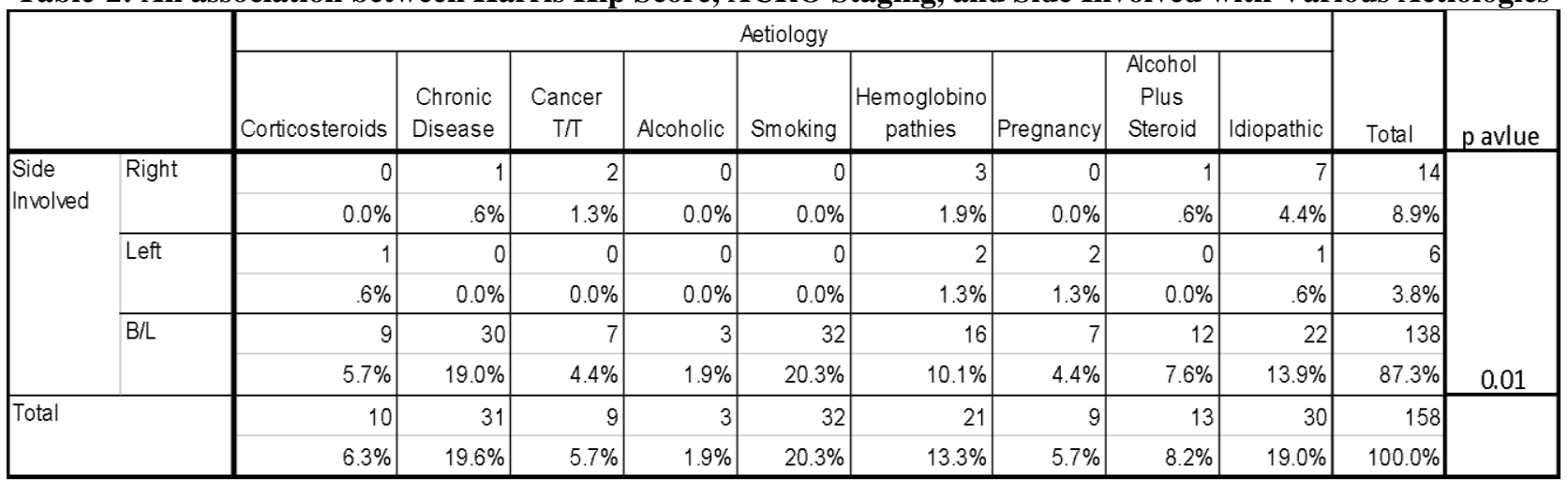

Table-3: An association with Side involved, Harris Hip Score and ACRO staging was checked with Treatment modalities employed

\begin{tabular}{|c|c|c|c|c|c|}
\hline & \multicolumn{2}{|l|}{ Treatment Given } & \multirow[t]{2}{*}{ Total } & \multirow[t]{2}{*}{ p value } \\
\hline & & Pharmacological & Surgical & & \\
\hline \multirow[t]{6}{*}{ Side Involved } & \multirow[t]{2}{*}{ Right } & 14 & 0 & 14 & \multirow[t]{6}{*}{0.001} \\
\hline & & $8.9 \%$ & $0.0 \%$ & $8.9 \%$ & \\
\hline & \multirow[t]{2}{*}{ Left } & 5 & 1 & 6 & \\
\hline & & $3.2 \%$ & $.6 \%$ & $3.8 \%$ & \\
\hline & \multirow[t]{2}{*}{$\mathrm{B} / \mathrm{L}$} & 24 & 114 & 138 & \\
\hline & & $15.2 \%$ & $72.2 \%$ & $87.3 \%$ & \\
\hline \multirow[t]{8}{*}{ Harris Hip Score } & \multirow[t]{2}{*}{$<70$} & 23 & 35 & 58 & \multirow[t]{8}{*}{0.017} \\
\hline & & $14.6 \%$ & $22.2 \%$ & $36.7 \%$ & \\
\hline & \multirow[t]{2}{*}{ 70-79 } & 14 & 48 & 62 & \\
\hline & & $8.9 \%$ & $30.4 \%$ & $39.2 \%$ & \\
\hline & \multirow[t]{2}{*}{$80-89$} & 6 & 19 & 25 & \\
\hline & & $3.8 \%$ & $12.0 \%$ & $15.8 \%$ & \\
\hline & \multirow[t]{2}{*}{$>90$} & 0 & 13 & 13 & \\
\hline & & $0.0 \%$ & $8.2 \%$ & $8.2 \%$ & \\
\hline \multirow[t]{8}{*}{ ACRO Staging } & \multirow[t]{2}{*}{ Stage 1} & 12 & 30 & 42 & \multirow[t]{8}{*}{0.015} \\
\hline & & $7.6 \%$ & $19.0 \%$ & $26.6 \%$ & \\
\hline & \multirow[t]{2}{*}{ Stage 2} & 13 & 15 & 28 & \\
\hline & & $8.2 \%$ & $9.5 \%$ & $17.7 \%$ & \\
\hline & \multirow[t]{2}{*}{ Stage 3} & 17 & 51 & 68 & \\
\hline & & $10.8 \%$ & $32.3 \%$ & $43.0 \%$ & \\
\hline & \multirow[t]{2}{*}{ Stage 4} & 1 & 19 & 20 & \\
\hline & & $.6 \%$ & $12.0 \%$ & $12.7 \%$ & \\
\hline \multirow{2}{*}{\multicolumn{2}{|c|}{ Total }} & 43 & 115 & 158 & \\
\hline & & $27.2 \%$ & $72.8 \%$ & $100.0 \%$ & \\
\hline
\end{tabular}

Table-4: Association with Surgical Methods employed and ACRO staging

\begin{tabular}{|c|c|c|c|c|c|c|}
\hline & \multicolumn{3}{|c|}{ Surgical Method } & \multirow[t]{2}{*}{ Total } & \multirow[t]{2}{*}{ p value } \\
\hline & & $\begin{array}{l}\text { Core } \\
\text { decompression }\end{array}$ & $\begin{array}{l}\text { Vascularized free } \\
\text { Fibular Graft }\end{array}$ & Total Hip Replacement & & \\
\hline \multirow{8}{*}{ ACRO Staging } & \multirow[t]{2}{*}{ Stage 1} & 16 & 14 & 0 & 30 & \multirow[t]{8}{*}{0.001} \\
\hline & & $13.9 \%$ & $12.2 \%$ & $0.0 \%$ & $26.1 \%$ & \\
\hline & \multirow[t]{2}{*}{ Stage 2} & 4 & 9 & 2 & 15 & \\
\hline & & $3.5 \%$ & $7.8 \%$ & $1.7 \%$ & $13.0 \%$ & \\
\hline & \multirow[t]{2}{*}{ Stage 3} & 26 & 22 & 3 & 51 & \\
\hline & & $22.6 \%$ & $19.1 \%$ & $2.6 \%$ & $44.3 \%$ & \\
\hline & \multirow[t]{2}{*}{ Stage 4} & 0 & 15 & 4 & 19 & \\
\hline & & $0.0 \%$ & $13.0 \%$ & $3.5 \%$ & $16.5 \%$ & \\
\hline \multirow{2}{*}{\multicolumn{2}{|c|}{ Total }} & 46 & 60 & 9 & 115 & \\
\hline & & $40.0 \%$ & $52.2 \%$ & $7.8 \%$ & $100.0 \%$ & \\
\hline
\end{tabular}




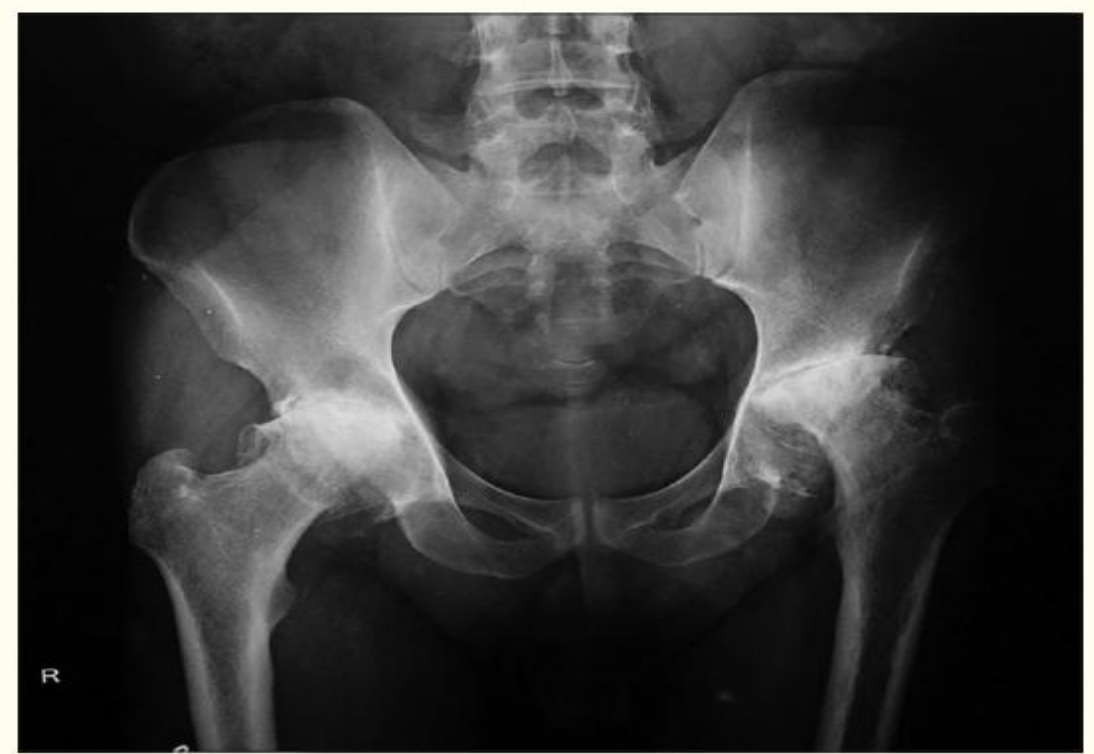

Fig-1: X ray Pelvis Antero Posterior view, steroid induced B/L AVN femoral head /hip

\section{DISCUSSION}

Indian evidence regarding the prevalence of AVN Hip is negligible. In the united states owing to better registries more than 20,000 new cases are diagnosed annually [17].

Few studies are hospital based and have sample sizes less than 300 patients. Evidence from the Japanese researchers put the mean age around 40 in male while around 30 in females. Evidence from Korean data puts the age on slightly higher side around 50 s, while studies from china puts the mean age to be 48 years [18].

In our study the mean age was 51.94 years which is older than the earlier reported evidence from India.

Its seen that in Asian population the older males are more often ailing from AVN Hip. Like above mentioned studies our study too had more males $(88 \%)$. No clear reasons for this can be ascertained unless more research is done on this regards.

We observed $87 \% \mathrm{~B} / \mathrm{L}$ involvement of hip joint whereas earlier studies reported have shown more pre ponderous of $\mathrm{B} / \mathrm{L}$ hip but not having more than $80 \%$ involvement. One reason might be the fact that most kept ignoring the pain till both hips were involved with AVN Hip [19].

Studies from Japan, China and Korea have had $\mathrm{B} / \mathrm{L}$ involvement in $67-75 \%$ cases. Consumption of alcohol $(20 \%-40 \%)$, corticosteroid therapy $(35 \%-40 \%)$ and idiopathy $(20 \%-40 \%)$ are among the various causes of AVN Hip widespread in the United States.
In Japan, corticosteroid was the most common cause of ONFH (51\%), followed by chronic consumption of alcohol (31\%).

The key risk factor for the occurrence of avascular necrosis of the femoral head is trauma in England.

In North Indian people in $37.3 \%$ of the patients with AVN Hip, accompanied by chronic consumption of alcohol (20.1\%), trauma (15.3\%) and and miscellaneous conditions were found. There was no identifiable danger in $21.3 \%$ of patients.

In our study we found idiopathic origin, smoking, chronic diseases including renal disease owing to diabetes and hypertension to be more common causes.

ARCO's international classification and HHS scoring were used to evaluate the extent of damage and stage of disease progression. This is in accordance with other studies done in India. In earlier studies they did found strong association with both these like we found in our study. In our study we had majority of patients with ACRO grading $3(43 \%)$ which shows the extent of damage they do before seeking medical care. HHS scoring too show similar story [20].

Treatment modality most commonly offered were either bone decompression or vascularized free fibular graft. We had refusals to surgical treatment which has been reported by earlier Indian studies too we didn't evaluated the post treatment outcomes in this study.

\section{CONCLUSION}

We can say that Idiopathic reasons coupled with chronic diseases and smoking were the more common reasons for patients coming with AVN Hip in 
our study population. Surgery is not readily acceptable to patients and more education needs to be done for them to understand when to seek early medical care.

\section{REFERENCES}

1. Mankin, H. J. (1992). Nontraumatic necrosis of bone (osteonecrosis). New England Journal of Medicine, 326(22), 1473-1479.

2. Cooper C, Steinbuch M, Stevenson R, Miday R, Watts NB. The epidemiology of osteonecrosis: findings from the GPRD and THIN databases in the UK. Osteoporosis international. 2010 Apr 1;21(4):569-77.

3. Lieberman JR, Berry DJ, Mont MA, Aaron RK, Callaghan JJ, Rajadhyaksha AD, Urbaniak JR. Osteonecrosis of the hip: management in the 21st century. Instructional course lectures. 2003 Jan 1;52:337-55.

4. Aldridge 3rd JM, Urbaniak JR. Avascular necrosis of the femoral head: etiology, pathophysiology, classification, and current treatment guidelines. American journal of orthopedics (Belle Mead, NJ). 2004 Jul;33(7):327-332.

5. Ikeuchi K, Hasegawa Y, Seki T, Takegami Y, Amano $\mathrm{T}$, Ishiguro $\mathrm{N}$. Epidemiology of nontraumatic osteonecrosis of the femoral head in Japan. Modern rheumatology. 2015 Mar 4;25(2):278-81.

6. Min BW, Song KS, Cho CH, Lee SM, Lee KJ. Untreated asymptomatic hips in patients with osteonecrosis of the femoral head. Clinical orthopaedics and related research. 2008 May 1;466(5):1087-92.

7. Vardhan H, Tripathy SK, Sen RK, Aggarwal S, Goyal T. Epidemiological profile of femoral head osteonecrosis in the North Indian population. Indian journal of orthopaedics. 2018 Apr;52:140-6.

8. Kubo T, Ueshima K, Saito M, Ishida M, Arai Y, Fujiwara H. Clinical and basic research on steroid-induced osteonecrosis of the femoral head in Japan. Journal of Orthopaedic Science. 2016 Jul 1;21(4):407-13.

9. Mont MA, Jones LC, Hungerford DS. Nontraumatic osteonecrosis of the femoral head: Ten years later. J Bone Joint Surg Am. 2006;88:1117-32.

10. Koo KH, Kim R, Kim YS, Ahn IO, Cho SH, Song HR, Park YS, Kim H, Wang GJ. Risk period for developing osteonecrosis of the femoral head in patients on steroid treatment. Clin Rheumatol. 2002 Aug; 21(4):299-303.

11. Boskey AL, Raggio CL, Bullough PG, Kinnett JG. Changes in the bone tissue lipids in persons with steroid- and alcohol-induced osteonecrosis. Clin Orthop Relat Res. 1983; 172:289-95.

12. Colah RB, Mukherjee MB, Martin S, Ghosh K. Sickle cell disease in tribal populations in India. The Indian journal of medical research. 2015 May;141(5):509-515.

13. Hsu H, Nallamothu SV. Hip Osteonecrosis. [Updated 2020 Aug 10]. In: StatPearls [Internet]. Treasure Island (FL): StatPearls Publishing; 2020 Jan-. Available from: https://www.ncbi.nlm.nih.gov/books/NBK499954/

14. Sen RK. Management of avascular necrosis of femoral head at pre-collapse stage. Indian journal of orthopaedics. $2009 \mathrm{Jan} ; 43(1): 6$.

15. Sugano N, Kubo $\mathrm{T}$, Takaoka K, Ohzono K, Hotokebuchi T, Matsumoto T, Igarashi H, Ninomiya S. Diagnostic criteria for non-traumatic osteonecrosis of the femoral head: a multicentre study. The Journal of Bone and Joint Surgery. British volume. 1999 Jul;81(4):590-5.

16. Schmitt-Sody M, Kirchhoff C, Mayer W, Goebel M, Jansson V. Avascular necrosis of the femoral head: inter-and intraobserver variations of Ficat and ARCO classifications. International orthopaedics. 2008 Jun 1;32(3):283-7.

17. Lieberman JR, Berry DJ, Mont MA, Aaron RK, Callaghan JJ, Rajadhyaksha AD, Urbaniak JR. Osteonecrosis of the hip: management in the $21 \mathrm{st}$ century. Instructional course lectures. 2003 Jan 1;52:337-55.

18. Fukushima W, Fujioka M, Kubo T, Tamakoshi A, Nagai M, Hirota Y. Nationwide epidemiologic survey of idiopathic osteonecrosis of the femoral head. Clinical Orthopaedics and Related Research®. 2010 Oct 1;468(10):2715-24.

19. Wang XS, Zhuang QY, Weng XS, Jin LI, Jin JI, Qian WW. Etiological and clinical analysis of osteonecrosis of the femoral head in Chinese patients. Chinese medical journal. 2013 Jan 20;126(2):290-5.

20. Jacobs B. Epidemiology of traumatic and nontraumatic osteonecrosis. Clinical orthopaedics and related research. 1978 Jan 1(130):51-67. 